\title{
Collaborative web-based learning spaces: Introduction to Housing
}

\author{
N. Charalambous*, C. Sentieri** \\ * Department of Architecture, University of Cyprus \\ ** School of Architecture, University of Valencia, Spain
}

\begin{abstract}
This paper explores a collaborative web-based learning space named "Introduction to Housing" created in the context of the Erasmus Lifelong Learning Project OIKONET. The learning space mainly draws on the curriculum of the design studios in the Polytechnic University of Valencia and the University of Cyprus and includes work from a 3D Visual Communication course at the University of Belgrade. All learning activities developed in this learning space aim at the introduction of students to housing studies through a collaborative learning environment that cuts across traditional and institutional boundaries. The paper starts with a brief discussion on design studio teaching, its importance in architectural education and recent impacts of emerging information technologies on traditional teaching methods. The transformation of the traditional design studio learning into a "blended" learning environment is then discussed through the presentation of the web-based learning space. The paper concludes with a discussion of the participants' experience which renders the proposed learning space as a fruitful and potentially innovative learning environment. Tutors had the opportunity to incorporate blended learning in their teaching and get familiar with different and diverse teaching methods and learning resources in different academic environments. Participating students on the other hand, were exposed to different cultural and academic contexts and were able to experience different methods of learning through the virtual campus.
\end{abstract}

Keywords: Web based learning; blended learning; design studio; collaborative learning space

\section{Introduction}

The collaborative teaching activity described in this paper was initiated during the spring semester 2013-14, as part of the European research project OIKONET. The creation of a collaborative web-based learning space was proposed aiming at the introduction of first year students to architectural principles with a focus on housing studies. The new learning space builds on a pedagogic model developed and implemented in the OIKODOMOS virtual campus developed in previous projects (www.oikodomos.org) and is based on the collaborative design and implementation of sequences of learning activities. These activities are carried out in digital learning environments specifically developed for the project, as well as in seminars and design studios taking place at the participating universities.

The paper is mainly based on a reflection on the collaborative teaching process developed through the learning space "Introduction to housing" (available online at: http://www.oikodomos.org/workspaces/). Through the analysis of the collaborative process and the content of the learning space, the discussion is directed towards examining potentials and limitations of web-based collaborative learning activities in introducing housing issues to architecture students. It highlights the challenges for both teachers and students collaborating through a common pedagogic structure while exposed to a wider international academic audience within the OIKONET project (www.oikonet.org). Furthermore, the paper attempts to identify the benefits of exposing early year architecture students to an international learning community, gaining knowledge and skills related to a general yet context-specific topic such as housing in a design studio environment, the backbone of architectural education (Charalambous et al 2007, 2012). 


\section{DESIGN STUDIO TEACHING}

The design studio has undoubtedly been at the core of architectural design education since its inception in the 19th century. The traditional studio-based pedagogy has remained fairly stable and unchanged, based on the historical models of the Beaux-Arts and the Bauhaus. The "design project", as the vehicle for project-based learning was adopted on the assumption that the expertise needed by architects could only partially be learned through the traditional methods of knowledge and experience transmission. The perceived benefits of the design project was that it simulated, albeit in a simplified and directed way, the actual processes of professional activity by requiring students to apply their accumulated knowledge and skills in an integrated way to a design problem. The model of "practice informs teaching" in an integrated environment of theoretical and practice related artistic creativity and research can trace its origin back to the Bauhaus workshop at the beginning of the 20th century. Architecture students became familiar with the materials and the profession, while possessing at the same time theoretical knowledge and experience that enabled a comprehensive project development. The integration of different types of knowledge in architectural education through a collaborative environment has been a perennial concern since then (Cunningham 2005).

The overriding primacy given to the studio as the main forum for creative exploration, interaction and assimilation remains a common characteristic in architectural education (Charalambous et al 2007). Students encounter fundamental principles and skills in design, supported by analytical and abstract thinking, integration of design aims in visual environments, as well as cultural, technological and other parameters. However, research related to contemporary pedagogical approaches to the studio reveals considerable differences in the process of education of future architects around the world; schools of architecture adopt different models of how learning within a design studio may occur. In some situations (the year system), students will all work on the same project, within a shared studio environment for a whole semester or year. In other situations (the unit system), students from various backgrounds may work together in a similar way to the Fine Arts ateliers.

Although studio teaching is still based on the traditional models of design process new forms of research have been developed aiming at a redefinition of the landscape of architectural education and practice within the design studio. Advances of disciplines, specialization, material- and systems-science and digital technology have brought a radical change in the contextual frameworks in which architectural design and production are normally placed. A major concern has been the relationship between the digital and the analogue worlds which forms a central issue for architectural design, research and production. Advances in digital technologies are paving the way to achieve "integrated inter-, multi- or even trans-disciplinary design" - in all cases a type of practice that covers a mind-set of collaboration and cross-disciplinary communication and experimentation, visualization and research at all or possibly at different stages of the design process (Charalambous et al 2012, Nicolescu 1997). This approach requires designers to rethink alternative strategies in order to establish sound links between disciplines and specializations. An aptitude for exploration is needed for the entire design process, from the early conceptual stage until the production phase.

This observation implies rethinking buildings as integral systems rather than the juxtaposition of optimized and mono functional layers but also rethinking design pedagogy which needs to address the challenge of both virtual and analogue modes of 
design and collaboration. The web-based collaborative learning environment "Introduction to Housing" has been developed with the aim to address such concerns and to promote pedagogic innovation in the field of introductory housing studies.

\section{Methods}

\section{CREATING A COLLABORATIVE LEARNING SPACE}

The house is undoubtedly one of the most important vehicles of exploring the social and experiential dimensions of architecture. An understanding of the ways in which the house as a spatial form, relates to the social, the cultural, the individual in the context of the increasingly divided, complex and differentiated experiences of contemporary life, is an important concern for architecture educators across the globe. The pedagogic purpose of the web based learning space "Introduction to Housing" is to address such concerns through the collaborative design and implementation of sequences of learning activities that introduce students to the basic principles of the design of a house. These learning activities attempt to overcome boundaries between physical and digital learning spaces by promoting a blended learning approach across institutions.

As already mentioned contemporary pedagogical approaches to the studio reveal considerable differences in the process of education of architecture students; schools of architecture adopt different models of how learning within a design studio in general or a housing design studio in particular may occur. Each school has its own particular curriculum, timetable and educational culture. So, the first challenge faced in the design of this learning space was to agree on a common plan of collaborative teaching on this specific topic which reflects the pedagogic objectives of the participating institutions.

An important first step was to establish a common understanding of the educational processes and the language used to describe them; this was based on the pedagogic methodology developed in the OIKODOMOS virtual campus. The definition of goals and learning outcomes in conjunction with the method of aligned learning and teaching to describe the process by which learning would take place is therefore used

The web-based learning environment OIKODOMOS Workspaces (www.oikodomos.org/workspaces), developed in the previous OIKODOMOS projects with the support of the Life Long Learning Programme2007-2011, formed the pedagogic structure of the new learning space. The structure of the Workspace enabled architecture educators from the three participating institutions to design a joint learning structure made up of collaborative Learning Activities and Learning Tasks. The pedagogic model underlying the learning environment is based on the structure presented in Figure 1: 


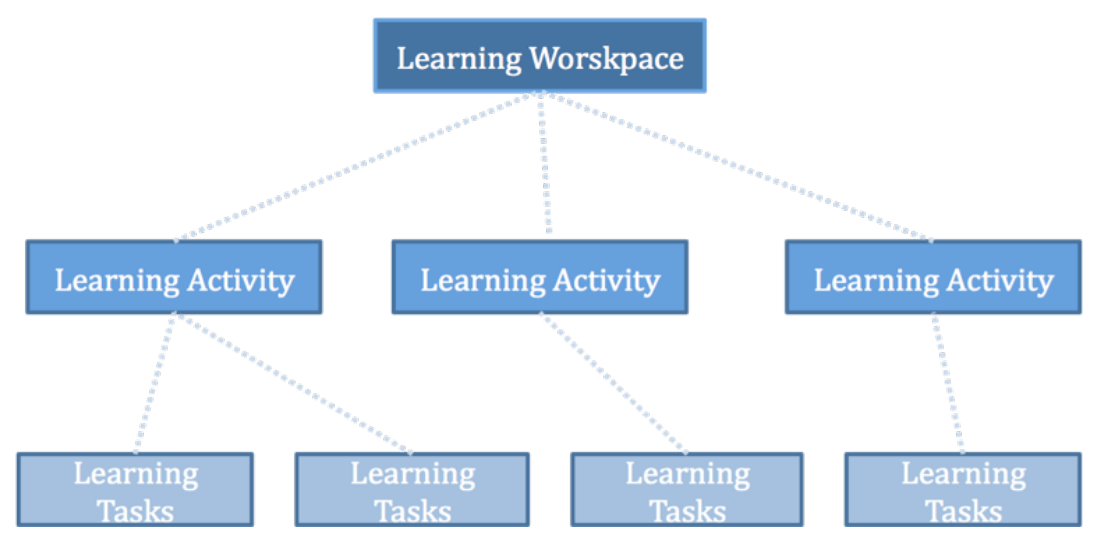

Figure 1. The pedagogic model of the collaborative learning environment "Introduction to Housing"

Learning Activities ${ }^{1}$ and Learning Tasks ${ }^{2}$ were collaboratively designed in alignment with the common pedagogic goals which are reflected in the learning outcomes set by the participating institutions. The underlying consideration is that everything to be assessed is supported by a learning process (http://www.oikodomos.org/resources/compendium.pdf). Teachers from the participating institutions aimed at collaboratively designed learning activities and tasks, describing at the same time the learning outcomes to be used to jointly assess students' work.

Learning Activities included precedents analysis, understanding of the concepts of home and house, context analysis and analysis of users' profiles. Learning Tasks included demonstration of knowledge of the relevant theoretical background, demonstration of coherence and continuity in the development of the design process, appropriate use of different representation techniques (verbally, textual and graphicdigital and analogue) in order to communicate the ideas (concepts and design proposals) in an effective manner, ability to demonstrate team working skills through their contribution to each project and ability to critique their own work and that of others by reference to established models of good practice and the appropriate standards. The Learning Activities and Learning tasks of the Workspace "Introduction to Housing" can be seen at www.oikodomos.org/workspaces, Figure 2.

\footnotetext{
${ }^{1}$ A Learning Activity is a well-defined stage in the process of learning, for instance, "Site analysis", "Analysis of precedents".

${ }^{2}$ A Learning Task is an assignment given to students within the context of a Learning Activity, for example,"Visual analysis of the site", "Studying a set of concepts".
} 


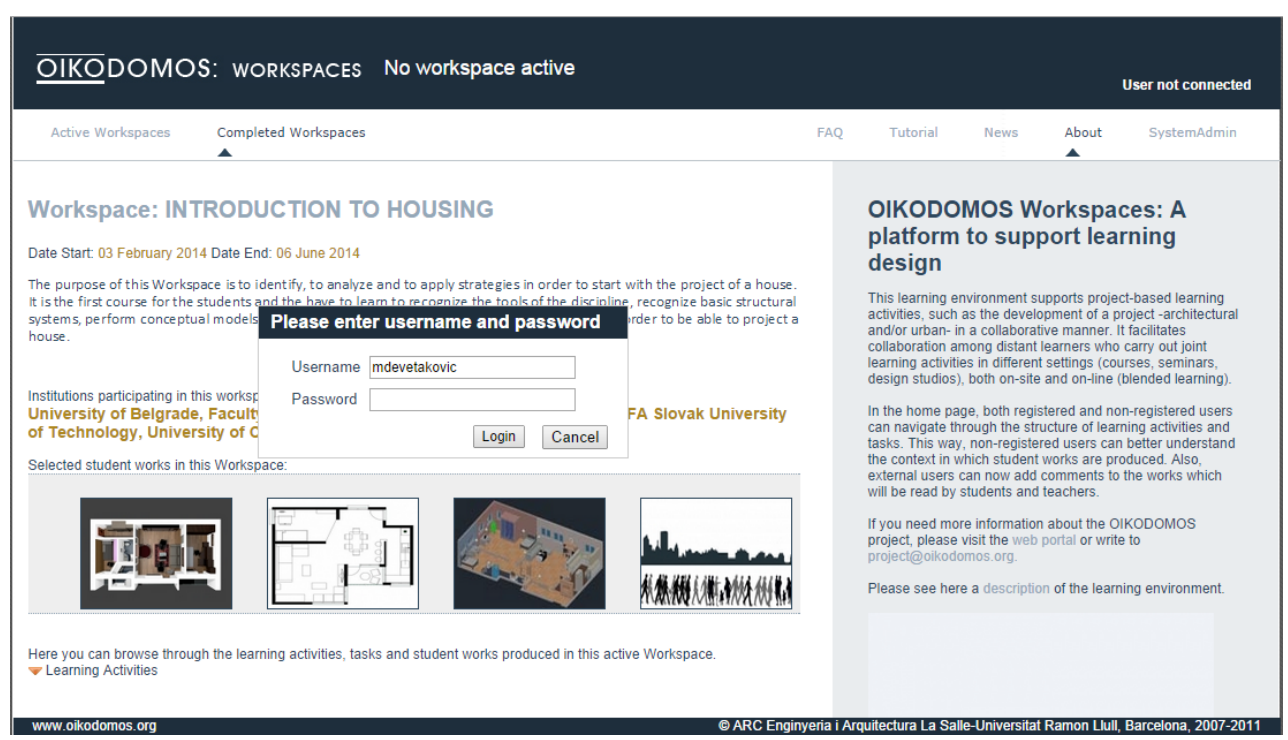

Figure 2. Home page of OIKODOMOS Workspaces

\section{Results and Discussion}

Each participating school implemented learning activities and tasks through the pedagogic structure of their curriculum. Overall, there were four groups of students enrolled with a total of 120 participants in the collaborative teaching and learning process. Final students' work was uploaded in the Workspace as deliverables, at the completion of each task. Students and tutors from all participating institutions were then invited to comment and give feedback to the submitted work, Figures 3 and 4.

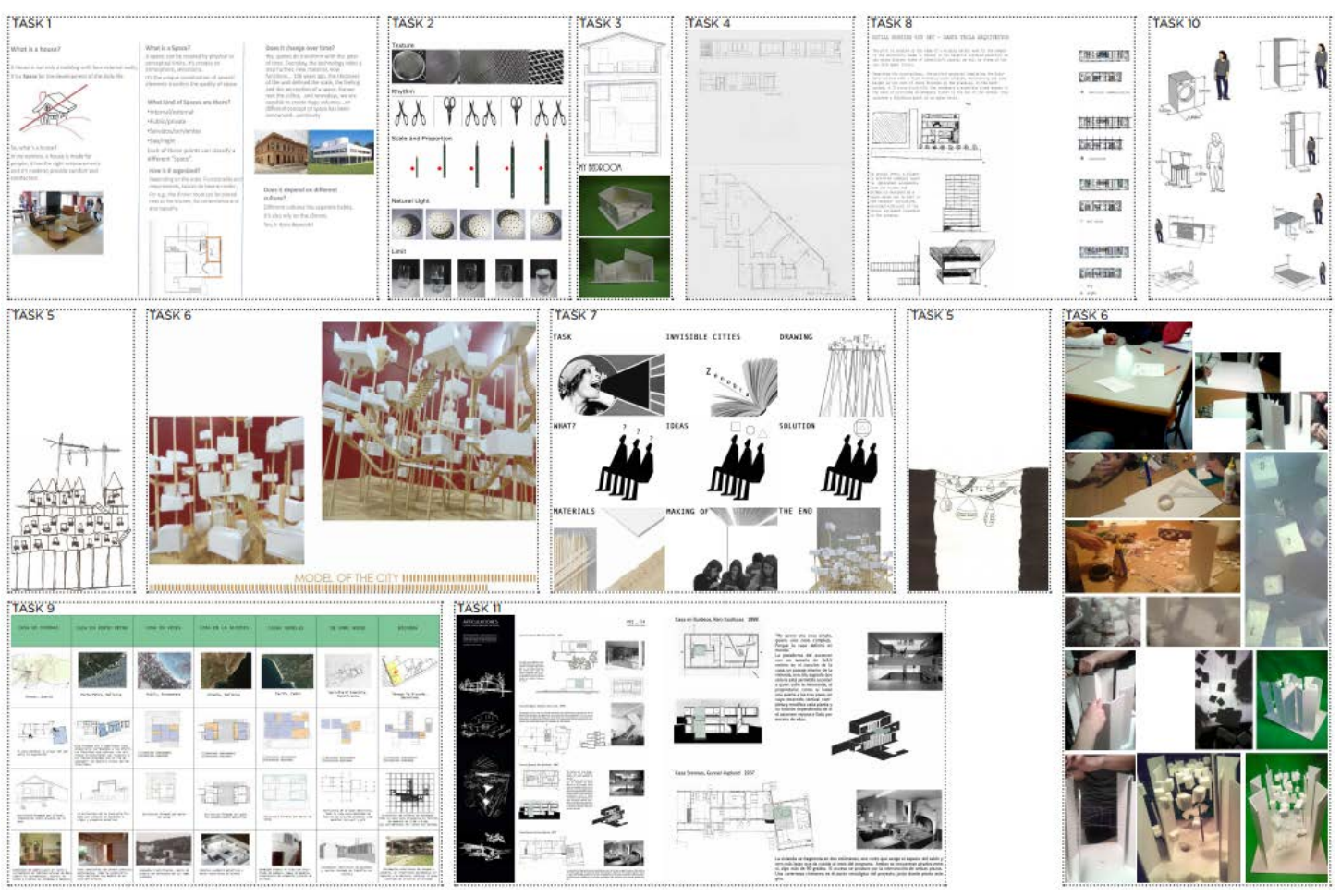

Figure 3. ETSAV students' deliverables 
The Workspace gave students the opportunity to be exposed to the work of fellow students but also to present their work to both students and colleagues from the participating schools. It also gave tutors the opportunity both to work in collaboration but also to come across diverse teaching methods as well as students work from other schools.

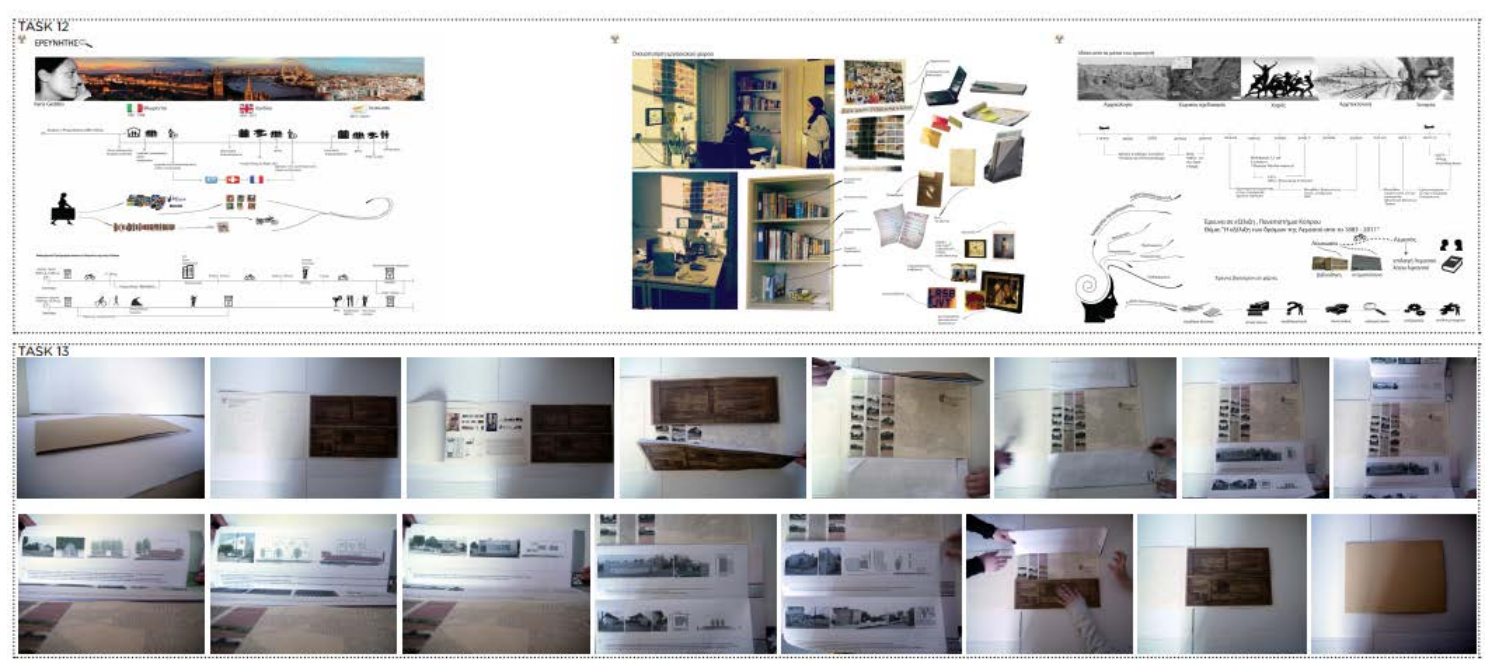

Figure 4. UCY students' deliverables

However, it proved that more time and better planning was required in order to make full use of the potentials of the Workspace. The learning environment has not been used to its full potential due to different deadlines set by the partner universities involved due to different starting and ending dates of the semesters; this did not facilitate a smooth collaborative building up of tasks (preceding and succeeding tasks). Work uploaded from partner universities was presented by the tutors and was discussed in class but students did not engage as actively as expected by themselves through the Workspace.

\section{Conclusions}

The teaching activity analyzed in this paper is regarded as the first in a series of similar activities that is going to be realized using the presented collaborative learning space "Introduction to Housing". The pedagogic structure created within this learning space is a base for future modifications and developments.

Both students and tutors found OIKODOMOS Workspaces a fruitful and potentially innovative learning environment. The tutors involved had the opportunity to incorporate blended learning in their teaching, get feedback from colleagues in different academic environments and get familiar with different and diverse teaching methods and learning resources. Participating students on the other hand, were exposed to different cultural and academic contexts, were able to experience different methods of learning through the virtual campus and had the opportunity to comment on other students' work but also receive feedback from both peers and tutors.

Participating teachers noted the potential of blended learning environments and OIKODOMOS Workspace technology to be used in an even more effective way, facilitating a more intensive interaction between students from various institutions and 
thus contributing to a better understanding of the multiplicity and complexity of housing issues.

\section{Acknowledgements}

OIKONET is an Erasmus Networks project co-financed by the Executive Agency Education, Audiovisual and Culture Executive of the European Union with the project number 539369-LLP-1-2013-ES-ERASMUS-ENW. We would like to thank our project partners who have contributed to the work reported in this paper.

\section{References}

Charalambous, N. and Phocas, M. (2012) "Research in the Studio: Integrated, Research Based Design Process", proceedings of the International conference Theory by Design: Architectural Research Made Explicit in the Design Teaching Studio, Antwerp, Belgium.

Charalambous, N. and Hadjisoteriou, M (2007) "Introductory Architectural Design Studio: (Re)Searching for a New Approach”, EAAE Transactions on Architectural Education: Teaching and Experimenting with Architectural Design: Advances in Technology and Changes in Pedagogy, No.35, pp. 285-293, Lisbon, Portugal.

Cunningham, A. (2005): Notes on education and research around architecture, The Journal of Architecture, 10:4, 415-441.

Devetakovic, M.; Arsic, P.; Nikolic, I. (2011). INTEGRATION OF E-LEARNING CONCEPTS IN URBAN DESIGN STUDIO, The case of a virtual learning environment supporting a specific educational mode , YU Info 2011, Kopaonik, March 2011, http://www.e-drustvo.org/proceedings/YuInfo2011/html/pdf/190.pdf (accessed September 2014)

Calvino, I. (1978) Invisible Cities, Harcourt Brace Jovanovich.

Madrazo, L. (2012): OIKODOMOS Technological Platform, in OIKODOMOS Innovating Housing Learning (ed. Madrazo, L.; Verbeke, J.; Ooms, T.; Riddy, P), pp. 48-61

Madrazo, L. (2011): OIKODOMOS Compendium, EU Lifelong Learning Programme retrieved from http://www.oikodomos.org/private/downloads/conferences/edulearn_oikodomos. pdf

Nicolescu, B. (1997). The transdisciplinary evolution of the university condition for sustainable development.

URL: http://www.perso.clubinternet.fr/nicol/ciret/bulletin/b12/b12c8.htm

Rasmussen S.E. (1964) Experiencing Architecture, Architecture (M.I.T Press)

Websites:

OIKODOMOS Project Website, Erasmus Lifelong Program 2009-2011. Available at http://www.oikodomos.org/.

OIKONET Project Website, 2014, Available at http://www.oikonet.org/ 